\section{Kidney \\ Blood Pressure Research}

Kidney Blood Press Res 2016;41:498-506

DOI: 10.1159/000443451

Published online: July 29, 2016

Accepted: May 31, 2016

\title{
Serum Alkaline Phosphatase Levels are Not Associated with Increased Death Risk in Prevalent Hemodialysis Patients: 5-Year Experience in a Single Hemodialysis Center
}

\author{
Jin-Gang Zhu ${ }^{a}$ Ben-Chung Cheng ${ }^{b}$ Wen-Chin Lee ${ }^{b}$ Lung-Chih Li ${ }^{b}$ \\ Chih-Hsiung Lee ${ }^{b}$ Gang Long ${ }^{a}$ Jin-Bor Chen ${ }^{b}$
}

aDepartment of Nephrology, Tianjin Union Medicine Center, Tianjin, P.R.China; ${ }^{b}$ Division of Nephrology, Department of Internal Medicine, Kaohsiung Chang Gung Memorial Hospital, Chang Gung University College of Medicine, Taiwan

\section{Key Words}

Alkaline Phosphatase $\cdot$ Hemodialysis $•$ Mortality

\begin{abstract}
Background/Aims: Although high serum alkaline phosphatase (ALP) levels were reported as predictive factors for death risk in dialysis patients on the basis of large databank analyses, the real scenario in a single hemodialysis (HD) center is unknown. Methods: In this study, a 5-year cohort of 1126 prevalent HD patients in the largest HD center in Taiwan was studied. The associations of ALP levels expressed as baseline, time-average, and time-dependent with allcause mortality and cardiovascular mortality were evaluated by using adjusted Cox regression models. Results: At baseline, levels of serum parathyroid hormone, calcium, and liver enzymes are increased in parallel with ALP quartiles. The hazard ratio (HR) for all-cause mortality was significantly increased in time-average and time-dependent ALP quartile in the unadjusted Cox analysis. The significance disappeared when multivariate adjusted Cox analysis was used. Similarly, HR was not significantly increased for cardiovascular mortality with ALP quartile expressed as baseline, time-average, and time-dependent in three models of Cox analyses. Conclusion: Our study demonstrated that serum ALP levels were not associated with increased death risk in prevalent HD patients over a 5-year interval.
\end{abstract}




\section{Kidney \\ Blood Pressure Research}

Zhu et al:: Alkaline Phosphatase Level with Death in Hemodialysis Patients

\section{Introduction}

Serum alkaline phosphatase (ALP) is a hydrolytic enzyme that removes phosphate from protein and nucleotides. Although it originates from many tissues in the human body, it is mainly concentrated in the bone and liver. Owing to its convenient measurement, serum ALP level is primarily used as an indicator for hepatic and bone disease. Serum ALP level reflects bone activity, including bone turnover and bone metabolism [1]. In chronic kidney disease (CKD) patients, serum ALP level is commonly used as a surrogate marker for hyperparathyroidism and renal bone disease. Generally, an elevated serum ALP level indicates high-turnover bone disease in CKD. Recently, emerging evidence from large-scale cohort studies suggests that serum ALP levels are associated with higher risk for mortality, not only in the general population but also in CKD patients. A report from the National Health and Nutrition Examination Survey in the US revealed a graded independent association between higher ALP levels and increased mortality in the general population [2]. Similarly, reports from pre-dialysis CKD studies showed that higher serum ALP levels are associated with increased all-cause mortality [3-5]. In dialysis patients, elevated serum ALP levels are also associated with increased mortality, independent of liver and bone metabolism parameters in both, hemodialysis (HD) and peritoneal dialysis patients [6-11].

Although the many aforementioned reports indicate a positive association of serum ALP levels with increased mortality in CKD, there are relatively few reports about this association in the Asian population. As the largest hospital-associated HD center in Taiwan, we intend to evaluate the association of serum ALP levels with all-cause and cardiovascular (CV) mortality in our prevalent HD cohort, over a 5-year interval.

\section{Patients and Methods}

The data of patients who received regular outpatient HD (three times per week) at Kaohsiung Chang Gung Memorial Hospital in Taiwan were collected. These patients were enrolled from January 1, 2009, to December 31, 2013. The records of a total of $1126 \mathrm{HD}$ patients who presented demographic data and routine laboratory data including CKD-MBD parameters at HD initiation were reviewed. Our exclusion criteria were as follows: (1) patients who did not receive regular HD thrice weekly; and (2) patients who did not receive regular HD for at least three subsequent months in our hospital.

Serial hemogram results and biochemical data between January 2009 and December 2013 were analyzed retrospectively. Values for certain blood parameters were measured monthly, with the exceptions of ferritin, which was measured every 3 months, as well as intact parathyroid hormone (iPTH), Kt/V urea score (Daugirdas method) [12], and urea reduction ratio, which were measured every 6 months. The URR was calculated by using the following equation:

[predialysis BUN - postdialysis BUN/predialysis BUN] $\times 100 \%$.

$\mathrm{Kt} / \mathrm{V}$ urea was calculated by using the following equation:

$\mathrm{Kt} / \mathrm{V}$ urea $=-\operatorname{Ln}(\mathrm{R}-0.008 \times \mathrm{t})+[4-(3.5 \times \mathrm{R})] \times \mathrm{UF} / \mathrm{W}$,

where $\mathrm{R}$ is the ratio of postdialysis and predialysis serum urea nitrogen, $\mathrm{t}$ (time in hours) is the duration of dialysis, UF (L) is the ultrafiltrate amount, and W (kilogram) is the postdialysis body weight. Corrected serum calcium was calculated by using the following equation:

measured total Ca $(\mathrm{mg} / \mathrm{dL})+0.8[4.0-$ serum albumin $(\mathrm{g} / \mathrm{dL})]$.

All blood parameters were measured using commercial kits and an autoanalyzer (Hitachi 7600210, Hitachi Ltd., Tokyo, Japan). Albumin was measured by the bromocresol green (BCG) method. For the measurement of CT ratio, chest radiography was performed after HD. Cardiac size was measured by drawing parallel lines on both sides of the heart, at the most lateral points on each side, and the distance between them was measured. Thoracic width was measured by drawing parallel lines down the inner aspect of the 


\section{Kidney \\ Blood Pressure Research}

widest points of the rib cage, and measuring the distance between these two points. Cardio-thoracic ratio is defined as cardiac size/thoracic width. All patients received HD with dialyzers that had an effective surface area of $>2.0 \mathrm{~m}^{2}$.

The protocol for the study was approved by the Committee on Human Research at Kaohsiung Chang Gung Memorial Hospital (101-1595B) for data review, and was conducted in accordance with the Declaration of Helsinki. The informed consents were not requested to be signed by the patients enrolled in our study, according to the regulation on retrospective data review by the Committee on Human Research at Kaohsiung Chang Gung Memorial Hospital.

\section{Statistical Methods and Demographics}

To investigate the characteristics of the study population, all patients were stratified into four categories $(\leq 66,67$ to 82,83 to 103 , and $\geq 104$ ), according to baseline serum ALP values collected when patients enrolled in the study. Baseline characteristics were analyzed as mean values with standard deviations for each group, and the difference between each serum ALP level was examined by using chi-squared test for categorical variables and analysis-of-variance. The Kruskal-Wallis test was used for continuous variables. The profile of baseline characteristics for age, sex, HD vintage, etiology of renal failure, EPO usage, vitamin-D usage, antihypertensive agent usage, iron (Fe) usage, parathyroidectomy status, and baseline laboratory data were assigned to the four groups according to the baseline serum ALP values. Baseline laboratory data included WBC count, albumin, $\mathrm{Hb}$, cholesterol, triglyceride, fasting blood glucose, AST (aspartate aminotransferase), ALT (alanine aminotransferase), total bilirubin, albumin-corrected calcium, P, K, uric acid, ferritin, iPTH, urea reduction ratio, Kt/V urea (Daugirdas) [13], and cardiac-thoracic ratio.

\section{Mortality (Cox model)}

The crude rates of mortality for all causes of death and CV disease mortality were both calculated for each baseline serum ALP group and tested with a chi-squared test. Further, in order to investigate the time of death (all cause and CV mortality) in the five-year cohort time, a series of Cox proportional hazards models were employed to evaluate the risk for the two kinds of mortalities. The three Cox models were constructed to include separately the baseline serum ALP levels, overall time-averaged (TA), and timedependent (TD) data for cohorts as the predictor variables. The ALP values in every year for each individual patient were averaged in the time-average model and annual data of ALP values per patient were treated as time-dependent explanatory variable in the time-dependent model. The discrete data of ALP $(\leq 66,67$ to 82,83 to 103 , and $\geq 104$ ) were tested as a fixed-effect variable. The data of patients who were alive before the end of study, while analyzing data, were defined as censored data according to specific definition of mortality.

Among the three survival models, the effect of ALP was estimated by hazard ratio with 95\% confidence interval in the unadjusted and covariates-adjusted analyses. Thus, the multivariable Cox model adjusted first for age, sex, HD vintage, etiology of renal failure, EPO usage, vitamin-D usage, antihypertensive agent usage, Fe usage, and parathyroidectomy status. In addition to these covariates, other baseline laboratory results were added to fit in the second multivariable Cox model (fully adjusted for iPTH, corrected Ca, and P).

\section{Results}

Patients were divided by quartiles of ALP levels at baseline. Patients with higher ALP levels were older. Female subjects were present in significantly higher percentage in the higher quartiles of ALP than male subjects. The trend for higher ALP quartiles revealed progressive increased in vitamin-D use. The lowest ALP quartile ( $\leq 66 \mathrm{U} / \mathrm{L})$ demonstrated higher percentage of cases with associated parathyroidectomy. Among laboratory parameters, serum albumin levels showed significant progressive decline toward the higher ALP quartiles. Serum corrected Ca, AST, ALT, total bilirubin, and iPTH levels demonstrated significant, progressive increase toward the higher ALP quartiles. The lowest cardiacthoracic ratio was significantly found in the lowest ALP quartile (Table 1). 


\section{Kidney \\ Blood Pressure Research}

Table 1. Summary of Demographics and Baseline Characteristics

\begin{tabular}{|c|c|c|c|c|c|}
\hline \multirow[t]{2}{*}{ Characteristic } & \multicolumn{5}{|c|}{ ALP (U/L) } \\
\hline & $\leq 66$ & 67 to 82 & 83 to 103 & $\geq 104$ & $\mathrm{p}$-value \\
\hline Number & 396 & 215 & 207 & 273 & \\
\hline Age (year) & $58.5 \pm 13.0$ & $60.2 \pm 12.1$ & $62.1 \pm 11.0$ & $60.4 \pm 12.4$ & 0.0056 \\
\hline \multicolumn{6}{|l|}{ Gender } \\
\hline Male & $213(53.79 \%)$ & $107(49.77 \%)$ & $100(48.31 \%)$ & $102(37.36 \%)$ & 0.0004 \\
\hline Female & $183(46.21 \%)$ & $108(50.23 \%)$ & $107(51.69 \%)$ & $171(62.64 \%)$ & \\
\hline $\begin{array}{l}\text { Hemodialysis vintage } \\
\text { (year) }\end{array}$ & $5.80 \pm 5.43$ & $5.54 \pm 5.27$ & $5.56 \pm 5.17$ & $6.19 \pm 5.28$ & 0.4984 \\
\hline \multicolumn{6}{|l|}{ Etiology of renal failure } \\
\hline Glomerulonephritis & $69(17.42 \%)$ & $31(14.42 \%)$ & $26(12.56 \%)$ & $44(16.12 \%)$ & 0.2878 \\
\hline Diabetes mellitus & $115(29.04 \%)$ & $68(31.63 \%)$ & $75(36.23 \%)$ & $72(26.37 \%)$ & \\
\hline Others & $212(53.54 \%)$ & $116(53.95 \%)$ & $106(51.21 \%)$ & $157(57.51 \%)$ & \\
\hline \multicolumn{6}{|l|}{ EPO use } \\
\hline Yes & $289(92.63 \%)$ & $154(92.22 \%)$ & $145(90.06 \%)$ & $205(87.61 \%)$ & 0.2057 \\
\hline No & $23(7.37 \%)$ & $13(7.78 \%)$ & $16(9.94 \%)$ & $29(12.39 \%)$ & \\
\hline Missing & 84 & 48 & 46 & 39 & \\
\hline \multicolumn{6}{|l|}{ Vitamin-D use } \\
\hline Yes & $65(16.54 \%)$ & $42(20.19 \%)$ & $45(22.28 \%)$ & $81(30.22 \%)$ & 0.0005 \\
\hline No & $328(83.46 \%)$ & $166(79.81 \%)$ & $157(77.72 \%)$ & $187(69.78 \%)$ & \\
\hline Missing & 3 & 7 & 5 & 5 & \\
\hline \multicolumn{6}{|c|}{ Antihypertensive agent use } \\
\hline Yes & $143(36.39 \%)$ & $75(36.06 \%)$ & $66(32.67 \%)$ & $93(34.70 \%)$ & 0.8244 \\
\hline No & $250(63.61 \%)$ & $133(63.94 \%)$ & $136(67.33 \%)$ & $175(65.30 \%)$ & \\
\hline Missing & 3 & 7 & 5 & 5 & \\
\hline \multicolumn{6}{|l|}{ Fe use } \\
\hline Yes & $38(9.67 \%)$ & $14(6.76 \%)$ & $20(9.90 \%)$ & $27(10.07 \%)$ & 0.5880 \\
\hline No & $355(90.33 \%)$ & $193(93.24 \%)$ & $182(90.10 \%)$ & $241(89.93 \%)$ & \\
\hline Missing & 3 & 8 & 5 & 5 & \\
\hline \multicolumn{6}{|l|}{ Parathyroidectomy } \\
\hline Yes & $87(22.14 \%)$ & $36(17.31 \%)$ & $27(13.37 \%)$ & $38(14.18 \%)$ & 0.0164 \\
\hline No & $306(77.86 \%)$ & $172(82.69 \%)$ & $175(86.63 \%)$ & $230(85.82 \%)$ & \\
\hline Missing & 3 & 7 & 5 & 5 & \\
\hline \multicolumn{6}{|l|}{ All-cause mortality } \\
\hline Yes & $75(18.94 \%)$ & $41(19.07 \%)$ & $40(19.32 \%)$ & $73(26.74 \%)$ & 0.0637 \\
\hline No & $321(81.06 \%)$ & $174(80.93 \%)$ & $167(80.68 \%)$ & $200(73.26 \%)$ & \\
\hline \multicolumn{6}{|l|}{ CV mortality } \\
\hline Yes & $15(3.79 \%)$ & $10(4.65 \%)$ & $7(3.38 \%)$ & $13(4.76 \%)$ & 0.8414 \\
\hline No & $381(96.21 \%)$ & $205(95.35 \%)$ & $200(96.62 \%)$ & $260(95.24 \%)$ & \\
\hline \multicolumn{6}{|c|}{ Baseline laboratory tests } \\
\hline Albumin $(\mathrm{gm} / \mathrm{dl})$ & $3.91 \pm 0.33$ & $3.87 \pm 0.30$ & $3.81 \pm 0.30$ & $3.75 \pm 0.40$ & $<.0001$ \\
\hline $\mathrm{Hb}(\mathrm{g} / \mathrm{dl})$ & $10.51 \pm 1.28$ & $10.71 \pm 1.23$ & $10.60 \pm 1.36$ & $10.38 \pm 1.54$ & 0.0457 \\
\hline Cholesterol (mg/dl) & $175.95 \pm 39.76$ & $178.70 \pm 40.73$ & $173.91 \pm 38.61$ & $175.67 \pm 43.09$ & 0.6778 \\
\hline Triglyceride (mg/dl) & $174.09 \pm 132.27$ & $168.77 \pm 137.49$ & $169.27 \pm 136.38$ & $148.31 \pm 114.17$ & 0.0797 \\
\hline Glucose (AC) (mg/dl) & $144.71 \pm 61.96$ & $148.77 \pm 74.61$ & $151.92 \pm 76.35$ & $152.95 \pm 79.99$ & 0.4674 \\
\hline Ferritin $(\mathrm{ng} / \mathrm{ml})$ & $494.79 \pm 442.49$ & $450.34 \pm 296.57$ & $505.13 \pm 453.62$ & $525.48 \pm 433.48$ & 0.2622 \\
\hline iPTH (pg/ml) & $186.44 \pm 194.46$ & $310.27 \pm 319.13$ & $356.12 \pm 320.06$ & $637.52 \pm 693.59$ & $<.0001$ \\
\hline Corrected Ca (mg/dl) & $9.15 \pm 0.74$ & $9.18 \pm 0.82$ & $9.28 \pm 0.90$ & $9.50 \pm 0.88$ & $<.0001$ \\
\hline $\mathrm{P}(\mathrm{mg} / \mathrm{dl})$ & $5.01 \pm 1.51$ & $4.82 \pm 1.40$ & $4.91 \pm 1.57$ & $4.73 \pm 1.55$ & 0.1176 \\
\hline $\mathrm{K}(\mathrm{meq} / \mathrm{l})$ & $4.97 \pm 0.72$ & $4.94 \pm 0.68$ & $4.96 \pm 0.81$ & $4.93 \pm 0.82$ & 0.9298 \\
\hline Uric acid $(\mathrm{mg} / \mathrm{dl})$ & $7.14 \pm 1.43$ & $7.12 \pm 1.41$ & $7.10 \pm 1.46$ & $6.98 \pm 1.36$ & 0.5311 \\
\hline Urea reduction ratio & $0.74 \pm 0.07$ & $0.74 \pm 0.07$ & $0.74 \pm 0.06$ & $0.75 \pm 0.07$ & 0.0503 \\
\hline Kt/V Daugirdas & $1.67 \pm 0.41$ & $1.68 \pm 0.49$ & $1.70 \pm 1.22$ & $1.71 \pm 0.39$ & 0.8530 \\
\hline Cardiac/thoracic ratio & $0.48 \pm 0.07$ & $0.50 \pm 0.07$ & $0.51 \pm 0.08$ & $0.51 \pm 0.08$ & $<.0001$ \\
\hline WBC (x1000/ul) & $6.16 \pm 1.77$ & $6.60 \pm 2.18$ & $6.46 \pm 3.03$ & $6.24 \pm 2.21$ & 0.0841 \\
\hline AST (IU/L) & $18.64 \pm 9.17$ & $19.04 \pm 7.75$ & $22.06 \pm 10.38$ & $27.97 \pm 39.37$ & $<.0001$ \\
\hline ALT (IU/L) & $15.66 \pm 10.55$ & $16.40 \pm 10.81$ & $19.45 \pm 12.48$ & $24.82 \pm 38.22$ & $<.0001$ \\
\hline Total Bilirubin $(\mathrm{mg} / \mathrm{dl})$ & $0.32 \pm 0.20$ & $0.33 \pm 0.17$ & $0.36 \pm 0.46$ & $0.39 \pm 0.27$ & 0.0255 \\
\hline \multicolumn{6}{|c|}{ HBsAg } \\
\hline Yes & $44(11.17 \%)$ & $29(13.49 \%)$ & $27(13.04 \%)$ & $34(12.55 \%)$ & 0.8330 \\
\hline No & $350(88.83 \%)$ & $186(86.51 \%)$ & $180(86.96 \%)$ & $237(87.45 \%)$ & \\
\hline Missing & 2 & 0 & 0 & 2 & \\
\hline \multicolumn{6}{|l|}{ Anti-HCV } \\
\hline Yes & $46(11.68 \%)$ & $26(12.09 \%)$ & $32(15.46 \%)$ & $36(13.28 \%)$ & 0.5945 \\
\hline No & $348(88.32 \%)$ & $189(87.91 \%)$ & $175(84.54 \%)$ & $235(86.72 \%)$ & \\
\hline Missing & 2 & 0 & 0 & 2 & \\
\hline
\end{tabular}




\section{Kidney Blood Pressure Research}

Table 2-1. Hazard Ratio of All-cause Mortality by Baseline Serum ALP Level

\begin{tabular}{|c|c|c|c|}
\hline & \multicolumn{3}{|c|}{ HR $(95 \%$ CI $)$} \\
\hline & Model 1 & Model 2 & Model 3 \\
\hline $\begin{array}{l}\text { ALP (U/L) } \\
\text { guartile 1 }<66)\end{array}$ & & 100 & \\
\hline $\begin{array}{l}\text { quartile } 1(\leq 66) \\
\text { quartile } 2(67 \text { to } 82)\end{array}$ & 0.90 (0.61 to 1.31$)$ & $0.96(0.63$ to 1.47$)$ & 0.99 (0.65 to 1.53$)$ \\
\hline quartile 3 ( 83 to 103 ) & 0.93 (0.64 to 1.37$)$ & $0.79(0.51$ to 1.21$)$ & 0.79 (0.51 to 1.22$)$ \\
\hline quartile $4(\geq 104)$ & $1.24(0.89$ to 1.71$)$ & $1.00(0.68$ to 1.49$)$ & $1.00(0.65$ to 1.54$)$ \\
\hline $\mathrm{P}$ for trend & 0.3005 & 0.6857 & 0.6763 \\
\hline
\end{tabular}

Cox regression model: Model 1: Unadjusted. Model 2: Adjusted for Age, Sex, Hemodialysis vintage, Etiology of renal failure, EPO, Vitamin-D, Antihypertensive agent, Fe use, and Parathyroidectomy + Baseline laboratory results (Albumin, $\mathrm{Hb}$, Cholesterol, Triglyceride, Glucose (AC), Ferritin, K, Uric acid, Urea reduction ratio, Kt/V Daugirdas, Cardiac/thoracic ratio, WBC, AST, ALT, Total Bilirubin, HBsAg, and Anti-HCV). Model 3: Model $2+$ Baseline laboratory results (iPTH, Corrected $\mathrm{Ca}, \mathrm{P}$ ).

Table 2-2. Hazard Ratio of All-cause Mortality by Average Serum ALP Level

\begin{tabular}{llll}
\hline & \multicolumn{3}{c}{ HR $(95 \%$ CI $)$} \\
\cline { 2 - 4 } & \multicolumn{1}{c}{ Model 1} & \multicolumn{1}{c}{ Model 3 } \\
\hline ALP (U/L) & 1.00 & 1.00 & 1.00 \\
quartile 1 $(\leq 66)$ & $0.92(0.61$ to 1.37$)$ & $0.94(0.59$ to 1.48$)$ & $0.91(0.57$ to 1.44$)$ \\
quartile 2 $(67$ to 82$)$ & $1.22(0.83$ to 1.79$)$ & $1.13(0.73$ to 1.75$)$ & $1.09(0.70$ to 1.70$)$ \\
quartile 3 $(83$ to 103$)$ & $1.66(1.19$ to 2.32$)$ & $0.96(0.62$ to 1.50$)$ & $0.91(0.57$ to 1.45$)$ \\
quartile 4 $(\geq 104)$ & 0.0031 & 0.8323 & 0.8020 \\
P for trend &
\end{tabular}

Cox regression model: Model 1: Unadjusted. Model 2: Adjusted for Age, Sex, Hemodialysis vintage, Etiology of renal failure, EPO, Vitamin-D, Antihypertensive agent, $\mathrm{Fe}$ use, and Parathyroidectomy + average laboratory results (Albumin, Hb, Cholesterol, Triglyceride, Glucose (AC), Ferritin, K, Uric acid, Urea reduction ratio, Kt/V Daugirdas, Cardiac/thoracic ratio, WBC, AST, ALT, Total Bilirubin, HBsAg, and Anti-HCV). Model 3: Model $2+$ average laboratory results (iPTH, Corrected $\mathrm{Ca}, \mathrm{P}$ ).

Table 2-3. Hazard Ratio of All-cause Mortality by Serum ALP Level, with a Time-dependent model

\begin{tabular}{|c|c|c|c|}
\hline & \multicolumn{3}{|c|}{ HR $(95 \%$ CI) } \\
\hline & Model 1 & Model 2 & Model 3 \\
\hline $\begin{array}{l}\text { ALP }(\mathrm{U} / \mathrm{L}) \\
\text { quartile } 1(\leq 66)\end{array}$ & 1.00 & 1.00 & 1.00 \\
\hline quartile $2(67$ to 82$)$ & $1.48(0.99$ to 2.21$)$ & $1.19(0.75$ to 1.89$)$ & $1.16(0.73$ to 1.86$)$ \\
\hline quartile 3 ( 83 to 103 ) & $1.36(0.91$ to 2.02$)$ & $1.65(1.05$ to 2.58$)$ & $1.62(1.02$ to 2.55$)$ \\
\hline quartile $4(\geq 104)$ & $1.97(1.41$ to 2.76$)$ & 1.65 (1.09 to 2.50$)$ & $1.60(1.03$ to 2.50$)$ \\
\hline $\mathrm{P}$ for trend & 0.0010 & 0.0618 & 0.0989 \\
\hline
\end{tabular}

Cox regression model: Model 1: Unadjusted. Model 2: Adjusted for Age, Sex, Hemodialysis vintage, Etiology of renal failure, EPO, Vitamin-D, Antihypertensive agent, Fe use, and Parathyroidectomy + laboratory results (Albumin, Hb, Cholesterol, Triglyceride, Glucose (AC), Ferritin, K, Uric acid, Urea reduction ratio, Kt/V Daugirdas, Cardiac/thoracic ratio, WBC, AST, ALT, Total Bilirubin, HBsAg, and Anti-HCV). Model 3: Model 2 + laboratory results (iPTH, Corrected $\mathrm{Ca}, \mathrm{P})$.

By Cox regression analyses, the hazard ratio (HR) for all-cause mortality was not significantly increased at baseline when ALP increased (Table 2-1). However, the HR for allcause mortality was significantly increased in the unadjusted TA model when ALP increased. The significance disappeared when fully adjusted (Table 2-2). The HR for ALP levels with allcause mortality in TD model showed a similar result (Table 2-3). HR for CV mortality was not significantly increased when increased ALP quartiles in the baseline and TA models (Table 3-1, 3-2). Although HR for CV mortality increased with increased ALP quartiles in the TD model, a significant statistical difference was not observed (Table 3-3). 


\section{Kidney \\ Blood Pressure Research}

Table 3-1. Hazard Ratio of CV Mortality by Baseline Serum ALP Level

\begin{tabular}{|c|c|c|c|}
\hline & \multicolumn{3}{|c|}{ HR $(95 \% \mathrm{CI})$} \\
\hline & Model 1 & Model 2 & Model 3 \\
\hline \multicolumn{4}{|l|}{ ALP (U/L) } \\
\hline quartile $1(\leq 66)$ & 1.00 & 1.00 & 1.00 \\
\hline quartile 2 (67 to 82$)$ & $1.12(0.50$ to 2.49$)$ & $1.11(0.44$ to 2.79$)$ & $1.17(0.45$ to 3.04$)$ \\
\hline quartile 3 (83 to 103$)$ & 0.83 (0.34 to 2.04$)$ & $0.80(0.30$ to 2.11$)$ & 0.84 (0.31 to 2.27$)$ \\
\hline quartile $4(\geq 104)$ & 1.07 (0.51 to 2.24$)$ & $0.71(0.27$ to 1.83$)$ & $0.71(0.25$ to 2.08$)$ \\
\hline $\mathrm{P}$ for trend & 0.9380 & 0.8248 & 0.8272 \\
\hline
\end{tabular}

Cox regression model: Model 1: Unadjusted. Model 2: Adjusted for Age, Sex, Hemodialysis vintage, Etiology of renal failure, EPO, Vitamin-D, Antihypertensive agent, Fe use, and Parathyroidectomy + Baseline laboratory results (Albumin, Hb, Cholesterol, Triglyceride, Glucose (AC), Ferritin, K, Uric acid, Urea reduction ratio, Kt/V Daugirdas, Cardiac/thoracic ratio, WBC, AST, ALT, Total Bilirubin, HBsAg, and Anti-HCV). Model 3: Model $2+$ Baseline laboratory results (iPTH, Corrected $\mathrm{Ca}, \mathrm{P})$.

Table 3-2. Hazard Ratio of CV Mortality by Average Serum ALP Level

\begin{tabular}{|c|c|c|c|}
\hline & \multicolumn{3}{|c|}{ HR $(95 \%$ CI) } \\
\hline & Model 1 & Model 2 & Model 3 \\
\hline \multicolumn{4}{|l|}{ ALP (U/L) } \\
\hline quartile $1(\leq 66)$ & 1.00 & 1.00 & 1.00 \\
\hline quartile 2 (67 to 82$)$ & $0.68(0.27$ to 1.69$)$ & $0.91(0.32$ to 2.55$)$ & $0.89(0.31$ to 2.53$)$ \\
\hline quartile 3 (83 to 103$)$ & $0.97(0.43$ to 2.21$)$ & $1.01(0.38$ to 2.69$)$ & $0.95(0.35$ to 2.59$)$ \\
\hline quartile $4(\geq 104)$ & $1.27(0.62$ to 2.61$)$ & $0.93(0.34$ to 2.52$)$ & $0.81(0.28$ to 2.36$)$ \\
\hline $\mathrm{P}$ for trend & 0.5687 & 0.9953 & 0.9796 \\
\hline \multicolumn{4}{|c|}{$\begin{array}{l}\text { Cox regression model: Model 1: Unadjusted. Model 2: Adjusted for Age, Sex, Hemodialysis } \\
\text { vintage, Etiology of renal failure, EPO, Vitamin-D, Antihypertensive agent, Fe use, and } \\
\text { Parathyroidectomy + average laboratory results (Albumin, Hb, Cholesterol, Triglyceride, Glucose } \\
\text { (AC), Ferritin, K, Uric acid, Urea reduction ratio, Kt/V Daugirdas, Cardiac/thoracic ratio, WBC, } \\
\text { AST, ALT, Total Bilirubin, HBsAg, and Anti-HCV). Model 3: Model } 2+\text { average laboratory } \\
\text { results (iPTH, Corrected Ca, P). }\end{array}$} \\
\hline
\end{tabular}

Table 3-3. Hazard Ratio of CV Mortality by Serum ALP Level, with a Time-dependent Model

\begin{tabular}{|c|c|c|c|}
\hline & \multicolumn{3}{|c|}{$\mathrm{HR}(95 \% \mathrm{CI})$} \\
\hline & Model 1 & Model 2 & Model 3 \\
\hline $\operatorname{ALP}(\mathrm{U} / \mathrm{L})$ & & & \\
\hline quartile $1(\leq 66)$ & 1.00 & 1.00 & \\
\hline quartile 2 (67 to 82$)$ & $1.54(0.64$ to 3.71$)$ & $1.20(0.40$ to 3.56$)$ & $1.23(0.41$ to 3.75$)$ \\
\hline quartile 3 (83 to 103 ) & $1.03(0.40$ to 2.66$)$ & $1.39(0.47$ to 4.11$)$ & $1.41(0.47$ to 4.24$)$ \\
\hline quartile $4(\geq 104)$ & $2.02(0.97$ to 4.24$)$ & $1.71(0.64$ to 4.55$)$ & $1.61(0.56$ to 4.60$)$ \\
\hline$P$ for trend & 0.2068 & 0.7350 & 0.8369 \\
\hline
\end{tabular}

Cox regression model: Model 1: Unadjusted. Model 2: Adjusted for Age, Sex, Hemodialysis vintage, Etiology of renal failure, EPO, Vitamin-D, Antihypertensive agent, Fe use, and Parathyroidectomy + laboratory results (Albumin, Hb, Cholesterol, Triglyceride, Glucose (AC), Ferritin, K, Uric acid, Urea reduction ratio, Kt/V Daugirdas, Cardiac/thoracic ratio, WBC, AST, ALT, Total Bilirubin, HBsAg, and Anti-HCV). Model 3: Model 2 + laboratory results (iPTH, Corrected $\mathrm{Ca}, \mathrm{P})$.

\section{Discussion}

The present study examined the association between serum ALP levels and mortality in one of the largest HD center in Taiwan. Baseline results showed that one-third of patients had serum ALP $\leq 66 \mathrm{U} / \mathrm{L}$, women were predominant in various strata of ALP levels, vitamin D use significantly increased toward higher percentage of patients when ALP levels increased, and the proportion of patients with history of parathyroidectomy increased toward the lower ALP strata. These associations between ALP trends, vitamin D use, and parathyroidectomy history is understandable from clinical experience. The sex distribution 


\section{Kidney Blood Pressure Research}

is similar to the prior reports [7, 8], when female subjects were reported with higher serum ALP levels than male subjects. Baseline laboratory parameter analysis revealed that higher serum albumin level was significant in the lowest serum ALP stratum, serum levels of iPTH and Ca were significantly higher for levels of ALP $\geq 104 \mathrm{U} / \mathrm{L}$, and liver enzyme (AST, ALT) and total bilirubin proportionally increased toward higher ALP strata. Again, most of laboratory parameters were associated with various strata of serum ALP levels, as mentioned in a previous study [7].

We examined the risk for mortality with Cox regression analyses using three ALP models (baseline, TA, TD). The HR was significantly increased for all-cause mortality toward higher levels of quartile (serum ALP $\leq 66 \mathrm{U} / \mathrm{L}$ was used as reference range because it included the largest proportion of patients in the range), with unadjusted TA and TD models. However, the significance disappeared when was fully adjusted and included iPTH, Ca, and P. Although HR was insignificantly increased for CV mortality by TD model toward higher ALP quartile, the risk for CV mortality in general is not associated with ALP increments by analyses with the three ALP models.

Of note, our results are different from those of the study of a cohort from DaVita databank. Their study exhibiting HR for all-cause death was increased based on timedependent ALP Cox regression model. The risk clearly increased $18 \%$ when serum ALP $\geq 180$ U/L [7]. The similar trend with association between serum high ALP levels and increased death risk are also noted in the two other studies, for serum ALP levels $>150 \mathrm{U} / \mathrm{L}$ and $>$ $120 \mathrm{U} / \mathrm{L}$ respectively $[8,14]$. Additionally, a report from Japan dialysis registry revealed that patients with highest ALP quartile had higher all-cause and CV mortalities on multivariate analysis [15]. The reason for the different results in the present study and some others is not clearly understood. The speculated reasons included a different reference range in serum ALP levels, relatively smaller number of cases and various interferences with therapeutic measures during the observation period.

Nevertheless, the possible mechanisms of ALP association with increased death in CKD have been provided in various studies. ALP increase has been demonstrated in vessels obtained from calcified arteriolopathy in CKD [16]. A hypothesis suggested that ALP is linked to vascular calcification through its role in mediating with pyrophosphate [17-19]. Further, indirect evidence suggested that ALP $>120 \mathrm{U} / \mathrm{L}$ had higher coronary artery calcification score [20]. Finally, ALP-death relationship may be possibly related to inflammation and osteomalacia. The latter may be resulting from 25-hydroxyvitamin D deficiency and that is an independent risk factor for inflammation and CV disease [21].

Present study has some limitations. First, it was designed as a retrospective study and selected subjects were all treated in one HD center. Center-specific effect cannot be excluded. Second, the diversity in clinical practice for different nephrologists could result in nonhomogenous management in CKD-MBD and that may result in different outcomes for death. Third, the sample size is relative small. However, present study provides a longitudinal 5-year observational data, and clearly demonstrated the relationship between increased death risk and increased serum ALP levels expressed by three models. Fourth, the definitive source of ALP, from bone or other tissues cannot be exactly verified. In the prior study, bone-specific ALP was demonstrated to be associated with bone turn-over following renal transplantation [22]. Moreover, higher serum bone-specific ALP was reported to be associated with the presence of vascular calcification in male HD patients [23]. However, we did not examine the relationship of bone-specific ALP levels and mortality in HD patients in the present study. We also found a constant parallel between increased liver enzymes and ALP levels in the present study. Thus, ALP from hepatobiliary is a contribution of risk for death and interference for statistical analysis. Finally, the contribution of inflammation to the increased death risk was not evaluated in the present study. Although we presented total circulating leukocyte count for analysis, which exhibited no association with baseline leukocyte count for serum ALP quartile, the association of inflammation status with death risk cannot be completely eliminated in the present study. 


\section{Kidney \\ Blood Pressure Research}

\begin{tabular}{l|l}
\hline Kidney Blood Press Res 2016;41:498-506 \\
\hline DOI: 10.1159/000443451 & (c) 2016 The Author(s). Published by S. Karger AG, Basel
\end{tabular}

Zhu et al:: Alkaline Phosphatase Level with Death in Hemodialysis Patients

\section{Conclusion}

We found that serum ALP levels were not associated with increased death risk in a cohort of prevalent HD patients, over a 5-year interval, by three Cox regression models analysis. Accordingly, the ALP-death relationship in prevalent HD patients needs to be verified in the future by studies done on a larger-scale and with longer observation period.

\section{Disclosure Statement}

The authors of this manuscript state that they do not have any conflict of interests and nothing to disclose.

\section{Acknowledgments}

The authors thank Eric Liu for his assistance with data management and statistical analysis.

\section{References}

1 Magnusson P, Sharp CA, Magnusson M, Risteli J, Davie MW, Larsson L: Effect of chronic renal failure on bone turnover and bone alkaline phosphatase isoforms. Kidney Int 2001;60:257-265.

2 Tonelli M, Curhan G, Pfeffer M, Sacks F, Thadhani R, Melamed ML, Wiebe N, Muntner P: Relation between alkaline phosphatase, serum phosphate, and all-cause or cardiovascular mortality. Circulation 2009;120:1784-1792.

3 Beddhu S, Ma X, Baird B, Cheung AK, Greene T: Serum alkaline phosphatase and mortality in African Americans with chronic kidney disease. Clin J Am Soc Nephrol 2009;4:1805-1810.

4 Kovesdy CP, Ureche V, Lu JL, Kalantar-Zadeh K: Outcome predictability of serum alkaline phosphatase in men with pre-dialysis CKD. Nephrol Dial Transplant 2010;25:3003-3011.

5 Taliercio JJ, Schold JD, Simon JF, Arrigain S, Tang A, Saab G, Nally JV Jr., Navaneethan SD: Prognostic importance of serum alkaline phosphatase in CKD stages 3-4 in a clinical population. Am J Kidney Dis 2013;62:703-710.

6 Blayney MJ, Pisoni RL, Bragg-Gresham JL, Bommer J, Piera L, Saito A, Akiba T, Keen ML, Young EW, Port FK: High alkaline phosphatase levels in hemodialysis patients are associated with higher risk of hospitalization and death. Kidney Int 2008;74:655-663.

7 Regidor DL, Kovesdy CP, Mehrotra R, Rambod M, Jing J, McAllister CJ, Van Wyck D, Kopple JD, KalantarZadeh K: Serum alkaline phosphatase predicts mortality among maintenance hemodialysis patients. J Am Soc Nephrol 2008;19:2193-2203.

8 Beddhu S, Baird B, Ma X, Cheung AK, Greene T: Serum alkaline phosphatase and mortality in hemodialysis patients. Clin Nephrol 2010;74:91-96.

9 Fein PA, Asadi S, Singh P, Hartman W, Stuto S, Chattopadhyay J, Avram MM: Relationship between alkaline phosphatase and all-cause mortality in peritoneal dialysis patients. Adv Perit Dial 2013;29:61-63.

10 Liu X, Guo Q, Feng X, Wang J, Wu J, Mao H, Huang F, Yu X, Yang X: Alkaline phosphatase and mortality in patients on peritoneal dialysis. Clin J Am Soc Nephrol 2014;9:771-778.

11 Nowak A, Artunc F, Serra AL, Pollock E, Krayenbühl PA, Müller C, Friedrich B: Sclerostin quo vadis? - is this a useful long-term mortality parameter in prevalent hemodialysis patients? Kidney Blood Press Res 2015;40:266-276.

12 Daugirdas JT: The post: pre-dialysis plasma urea nitrogen ratio to estimate K.t/V and NPCR: mathematical modeling. Int J Artif Organs 1989;12:411-419.

13 Daugirdas JT: The post: pre dialysis plasma urea nitrogen ratio to estimate K.t/V and NPCR: validation. Int J Artif Organs 1989;12:420-427. 


\section{Kidney \\ Blood Pressure Research}

14 Chang JF, Feng YF, Peng YS, Hsu SP, Pai MF, Chen HY, Wu HY, Yang JY: Combined alkaline phosphatase and phosphorus levels as a predictor of mortality in maintenance hemodialysis patients. Medicine 2014;93:e106.

15 Maruyama Y, Taniguchi M, Kazama JJ, Yokoyama K, Hosoya T, Yokoo T, Shigematsu T, Iseki K, Tsubakihara Y: A higher serum alkaline phosphatase is associated with the incidence of hip fracture and mortality among patients receiving hemodialysis in Japan. Nephrol Dial Transplant 2014;29:1532-1538.

16 Reslerova M, Moe SM: Vascular calcification in dialysis patients: pathogenesis and consequences. Am J Kidney Dis 2003;41:S96-99.

17 Schoppet M, Shanahan CM: Role for alkaline phosphatase as an inducer of vascular calcification in renal failure? Kidney Int 2008;73:989-991.

18 Lomashvili KA, Garg P, Narisawa S, Millan JL, O'Neill WC: Upregulation of alkaline phosphatase and pyrophosphate hydrolysis: potential mechanism for uremic vascular calcification. Kidney Int 2008;73:1024-1030.

19 Alesutan I, Musculus K, Castor T, Alzoubi K, Voelkl J, Lang F: Inhibition of Phosphate-Induced Vascular Smooth Muscle Cell Osteo-/Chondrogenic Signaling and Calcification by Bafilomycin A1 and Methylamine. Kidney Blood Press Res 2015;40:490-499.

20 Shantouf R, Kovesdy CP, Kim Y, Ahmadi N, Luna A, Luna C, Rambod M, Nissenson AR, Budoff MJ, KalantarZadeh K: Association of serum alkaline phosphatase with coronary artery calcification in maintenance hemodialysis patients. Clin J Am Soc Nephrol 2009;4:1106-1114.

21 Kovesdy CP, Kalantar-Zadeh K: Vitamin D receptor activation and survival in chronic kidney disease. Kidney Int 2008;73:1355-1363.

22 Cseprekál O, Kis E, Dégi AA, Kerti A, Szabó AJ, Reusz GS: Bone metabolism and arterial stiffness after renal transplantation. Kidney Blood Press Res 2014;39:507-515.

23 Ishimura E, Okuno S, Okazaki H, Norimine K, Yamakawa K, Yamakawa T, Shoji S, Nishizawa Y, Inaba M: Significant association between bone-specific alkaline phosphatase and vascular calcification of the hand arteries in male hemodialysis patients. Kidney Blood Press Res 2014;39:299-307. 